\title{
Eficiência, gestão e meio ambiente na carcinicultura do Rio Grande do Norte
}

\author{
Jorge Luiz Mariano da Silva ${ }^{1}$ \\ Luciano Menezes Bezerra Sampaio²
}

Resumo: Este artigo analisou a eficiência técnica de pequenos e médios produtores de camarão no Rio Grande do Norte em duas etapas. Na primeira, foram obtidos escores de eficiência por meio da estimação de fronteiras de produção não paramétricas DEA (Análise de Envoltória de Dados) e FDH (livre descarte). Em seguida, através da estimação de um modelo de regressão censoriada (Tobit) determinou-se a associação dos escores de eficiência com indicadores de gestão dos carcinicultores e a localização de suas fazendas. Os níveis de eficiência técnica foram mais altos para os sistemas de produção extensivo e semi-intensivo. Os resultados também revelaram que algumas práticas de gestão estão associadas aos escores de eficiência. Além disso, produtores localizados em estuários com menores níveis de emissões de nitrogênio e fósforo e, portanto, menos poluentes na média, obtiveram melhor eficiência técnica, ou seja, o melhor uso dos recursos de produção conecta-se a um menor impacto ambiental da atividade sobre os estuários do estado.

Palavras-chaves: carcinicultura, eficiência técnica e meio ambiente.

Abstract: This paper investigates shrimp small and median farms performance in Rio Grande do Norte in two steps. First, technical efficiency was estimated by nonparametric production frontiers, data envelopment analysis (DEA) and Free Disposal Hull (FDH). As a second stage, after DEA and FDH analysis, the degree of inefficiency was explained by

\footnotetext{
${ }^{1}$ Doutor em Economia pelo Pimes (UFPE). Professor Adjunto de Economia, Departamento de Economia (PPGR, UFRN).E-mail: jdal@ufrnet.br

${ }^{2}$ Professor Adjunto do Departamento e Pós-graduação em Administração da UFRN. Bolsista de produtividade do CNPq. Pós-doutorado na University of Illinois e Doutorado em Economia pelo Pimes (UFPE), em 2004, com estagio doutoral na Sorbonne/Paris 1. Email: Luciano.sampaio@pq.cnpq.br
} 
a statistical Tobit model, in terms of managerial indicators and localization. Average efficiencies were bigger for the extensive and semi-intensive production system. The results indicated that some managerial practices did not reduce the inefficiency. The localization affected inefficiency: producers within estuaries associated with the emissions of small amounts of nitrogen and phosphorus were efficient, i.e., a best use of inputs can reduce environmental impacts.

Key-words: shrimp production, technical efficiency e environment.

Classificação JEL: Q12, C14, C24.

\section{Introdução}

A carcinicultura brasileira destacou-se recentemente pela rápida expansão da produção e inserção no comércio internacional, com recorde de exportação em 2004 de quase trinta mil toneladas, correspondente a 116 milhões de dólares. Apesar da redução da taxa de crescimento das exportações, os volumes e valores foram da mesma ordem nos dois anos seguintes. No cenário nacional, o estado do Rio Grande do Norte (RN) é o principal exportador, respondendo por aproximadamente $45 \%$ do total exportado nos últimos três anos ${ }^{3}$.

Além da geração de divisas, a atividade é importante criadora de emprego e renda. Segundo Costa e Sampaio (2004), a cadeia produtiva de camarão cultivado no Brasil, constituída por laboratórios de pós-larvas, fazendas de engorda e centros de processamento, gera 1,89 empregos diretos e 1,86 empregos indiretos por hectare de viveiro em produção, totalizando 3,75 empregos por hectare e superando a geração de empregos de atividades tradicionais na região, como a fruticultura irrigada.

Por outro lado, questiona-se a sustentabilidade da atividade no longo prazo, dados os efeitos sobre o meio ambiente, mais precisamente dada à possível destruição dos manguezais dos estuários de toda costa litorânea do Rio Grande do Norte. A maioria dos ecossistemas litorâneos está submetida a impactos ambientais resultantes do excesso de nutrientes neles despejados, provenientes de diversos processos naturais e de atividades humanas (BRICKER et al., 2003). Estes impactos podem estar ligados a uma complexa cadeia de eventos (mudanças na estrutura da comunidade, cadeia alimentícia, proliferação de algas daninhas, redução no nível de oxigênio, redução da biodiversidade etc) que variam no espaço e no tempo, mas que podem ser identificados pela acumulação de excesso de nitrogênio e fósforo em águas fluviais em direção ao oceano (TAPPIN, 2002). Lacerda et al. (2006) destacaram que as acusações do impacto ambiental da atividade são, na maioria, associadas às emissões de grandes quantidades de nitrogênio $(\mathrm{N})$ e fósforo $(\mathrm{P})$ nos

${ }^{3}$ Dados do Ministério do Desenvolvimento Indústria e Comércio Exterior. Aliceweb. http://www.desenvolvimento.gov.br. 
estuários. Eles estimaram, para os estuários do Rio Grande do Norte, usando uma abordagem de fator de emissão, as emissões anuais de $\mathrm{N}$ e P das fazendas de camarão e de outras fontes como agricultura e, ainda, de processos naturais.

De acordo com o último Censo da Associação Brasileira dos Criadores de Camarão (ABCC, 2004), em 2004, o Rio Grande do Norte produziu 30.784 toneladas de camarão de um total produzido pelo Brasil de 72.898 toneladas, representando, aproximadamente, $42 \%$ da produção nacional, o que correspondeu ainda a $38 \%$ da área total de viveiros e $38,2 \%$ do total de produtores. Uma peculiaridade da produção no $\mathrm{RN}$, em relação aos demais estados de destaque, é o grande número de pequenos produtores. No Ceará, segundo maior produtor nacional, há 22 produtores com até 2 hectares do total de 191 registrados no Censo de 2004, ou seja, $12 \%$, enquanto no RN 119 do total de 375 produtores têm até dois hectares (32\% do total). Acrescenta-se ainda que o número de produtores do RN com área inferior a 30 hectares compreendeu $92 \%$ de seu total no mesmo ano. Segundo publicação da ABCC (ROCHA; RODRIGUES, 2003), são considerados produtores pequenos e médios aqueles com área de produção inferior a 50 ha.

A maior dificuldade de exportação ${ }^{4}$, aliada à importância da atividade no $\mathrm{RN}$, indica a necessidade de aperfeiçoar o sistema produtivo com melhor uso dos recursos, resultando em maior eficiência na produção, e conseqüentes ganhos de competitividade. Uma maior eficiência técnica também pode proporcionar uma redução no impacto ambiental da atividade sobre os estuários do estado e do Nordeste.

Ainda, espera-se que o potencial para aumento de eficiência seja maior nos casos dos pequenos e médios produtores, os quais, em geral, têm menor disponibilidade de recursos próprios, maiores dificuldades de acesso ao crédito e, conseqüentemente, à assistência técnica. Especificamente para o grupo de pequenos e médios, acrescentam-se menor grau de instrução e baixa capacitação para desenvolvimento da atividade, colocando-os entre os que mais podem ser afetados por políticas públicas voltadas para melhora da eficiência.

Portanto, esse estudo tem como objetivo principal avaliar o grau de eficiência dos pequenos e médios produtores localizados no Rio Grande do Norte, além de tentar explicar a eficiência por meio de indicadores de localização e de práticas de gestão da atividade. Como objetivo específico está a associação entre as eficiências calculadas dos produtores e as emissões de poluentes (nitrogênio e fósforo) dos estuários onde estão localizados os produtores. A metodologia da pesquisa consiste em aplicar os métodos de análise de envoltória de dados (Data Envelopment Analysis - DEA e Free Disposal Hull - FDH) para medir o grau de eficiência técnica dos produtores e inferir, através da análise do modelo de regressão Tobit, quais variáveis (de gestão e localização) explicam as ineficiências dos mesmos.

\footnotetext{
${ }^{4}$ As exportações brasileiras de camarão foram prejudicadas, sobretudo em 2003, pela política de anti-dumping americana e também perderam competitividade com a valorização do real nos últimos anos.
} 
Além desta introdução, o trabalho apresenta, na seção 2, uma breve revisão sobre a aplicação de modelos de eficiência na carcinicultura internacional e brasileira. A seção 3 descreve a metodologia empregada para o cálculo dos escores de eficiência, as variáveis, os dados utilizados e o método de regressão censoriada. Apresentam-se e discutem-se os resultados na seção 4 . A seção 5 traz as conclusões e considerações finais.

\section{Eficiência na carcinicultura: uma breve revisão da literatura}

Dois trabalhos de Gunaratne e Leung são referências na literatura internacional sobre a eficiência técnica na carcinicultura. No primeiro trabalho, em 1996, os autores estimaram um modelo de fronteira de produção para analisar as características da produção e os níveis de eficiência técnica entre produtores dos principais países da Ásia. Eles analisaram o desempenho produtivo dos carcinicultores em relação às fronteiras de produção de cada país e em relação à fronteira de produção regional. Para tanto, os autores classificaram os produtores por sistemas de produção extensivo, semi-intensivo e intensivo. Na estimação das fronteiras de produção, o valor da produção de camarão foi analisado em relação aos seguintes insumos: mão-de-obra, ração e pós-larva. Ainda foram incluídas no modelo variáveis dummies específicas para cada país. Os resultados de eficiência calculados foram explicados, em um processo de regressão de dois passos, pelas seguintes variáveis: tamanho da fazenda, experiência do carcinicultor, propriedade da terra e indicadores gerenciais relacionados à utilização de água e ração. As eficiências técnicas médias dos tipos de sistemas extensivo, semi-intensivo e intensivo -, em uma escala que varia de 0 a 1 , sendo 1 atribuído ao produtor eficiente (situado na fronteira de produção eficiente), foram estimadas, respectivamente, em 0,49, 0,60 e 0,57 e, portanto, não apresentaram grandes variações de um tipo de sistema para outro. Contudo, os autores ressaltaram que as médias disfarçaram as variações consideráveis dentro de cada tipo de sistema de um país para outro. No sistema extensivo, por exemplo, a eficiência técnica variou de 0,35 (para o Vietnam) a 0,61 (para Índia); no semi-intensivo, de 0,37 (para o Vietnam) a 0,69 (para o Sri Lanka); e no sistema intensivo, de 0,47 (para Taiwan) a 0,79 (para Sri Lanka). Os países com maiores potenciais para ganhos de eficiência foram: no sistema extensivo, a Índia; no semi-intensivo, o Sri Lanka e a Malásia; e no intensivo, os dois últimos além das Filipinas. A análise indicou que a melhora da eficiência pode ser conseguida, sobretudo, com adoção de tecnologias mais adequadas para a região.

O estudo de Gunaratne e Leung (1996) ainda apresentou um cálculo dos ganhos financeiros por hectare, caso os produtores dos países asiáticos passassem a operar sobre a fronteira de produção regional, que poderiam ser, em 
média, de US\$ 4.200, US\$ 11.000 e US\$ 34.000 para os sistemas de produção extensivo, semi-intensivo e intensivo, respectivamente. Os resultados das regressões, que explicaram as eficiências dos produtores, mostraram que o tamanho das fazendas tem um impacto negativo sobre a eficiência técnica dos produtores dos sistemas extensivo e semi-intensivo e um efeito positivo sobre os produtores do sistema intensivo; a experiência estava positivamente associada com a eficiência técnica, enquanto que a operação da atividade pelo proprietário apresentou uma associação negativa com a mesma; o gerenciamento sobre a utilização da água e da ração teve um efeito positivo sobre a eficiência técnica da produção de camarão.

Em outro artigo, Gunaratne e Leung (1997) conduziram uma análise comparativa entre fronteira de produção estocástica e a técnica não-paramétrica de análise de envoltória de dados (DEA). Eles estimaram a eficiência técnica, alocativa e econômica para produtores intensivos e semi-intensivos de camarão na Malásia. Na média, as eficiências técnica, alocativa e econômica foram similares nos dois sistemas de produção. Eles mostraram potencial substancial para aumentar o nível de produção de camarão usando os insumos e a tecnologia existentes de forma mais eficiente, em ambos os sistemas. Este fato questiona a tendência atual de intensificação da produção de camarão e a percepção de que isto possa aumentar a eficiência. Em ambos os sistemas, na média, os níveis ótimos de ração e pós-larva são maiores que os empregados atualmente.

Martinez-Cordero e Leung (2004) utilizaram uma amostra de fazendas produtoras de camarão, no sistema semi-intensivo, para os períodos de $1994 \mathrm{e}$ 1996-1998 no nordeste do México. Eles obtiveram indicadores do desempenho de eficiência ajustados para incorporar impactos ambientais, sobretudo a substituição de uma espécie por outra (de camarão branco para azul) como conseqüência de uma doença viral. Assim, a eficiência e a produtividade foram medidas e analisadas em correspondência com três eventos: uso de camarão branco ou azul; quebra viral no desempenho da produção; e adaptação de trabalho a uma nova espécie, após 1996. Usando uma abordagem de função distância, com orientação insumo, foram examinadas a produtividade total dos fatores (TPF) e a eficiência técnica, esta última usando as abordagens tradicional e ajustada para o meio ambiente. A TPF foi menor em 1996/1998 em relação a 1994, refletindo o aumento do uso de tecnologia de produção insumo-intensiva. A mudança de espécies implicou aumento do uso de água e de emissões poluentes, apesar do aumento de produtividade.

Para o Brasil, destacam-se duas referências de um mesmo autor: Sousa Júnior (2003) e Sousa Júnior et al. (2005). Em ambos os trabalhos os autores utilizaram o DEA para analisar a eficiência técnica, alocativa e econômica para uma amostra de 68 produtores do Ceará, representativa de uma população de 210 produtores. Os insumos utilizados foram: trabalho contratado (permanente ou temporário), pós-larvas, ração, fertilizante, produtos para correção, defensivos e energia 
elétrica. Do total, 38 foram classificados como eficientes - medidas de eficiência técnica entre 0,9 e 1,0. Constatou-se uma possível redução de insumos dos ineficientes da ordem de $19,11 \%$. A combinação ótima de insumos deveria reduzir o custo operacional em $37,13 \%$.

\section{Metodologia}

Para medir a eficiência dos pequenos e médios produtores de camarão do Rio Grande do Norte foram estimadas três fronteiras não-paramétricas: duas do tipo DEA - uma com retornos constantes de escala, DEA-C, e a outra com retornos variáveis de escala, DEA-V - apresentadas em 3.1, e uma terceira admitindo os pressupostos do modelo FDH (seção 3.2). Em 3.3 descreveram-se as variáveis e dados do trabalho e em 3.4, o método de regressão Tobit, o qual foi usado para explicar a ineficiência através de variáveis selecionadas.

\subsection{A abordagem DEA}

O grau de eficiência dos produtores de camarão foi determinado pelo método de análise de envoltória de dados DEA 5 . Neste método, as fazendas de camarão são consideradas unidades de tomada de decisão (Decision Making Units - DMUs), as quais são avaliadas por suas eficiências relativas às unidades identificadas como eficientes e que compõem a fronteira tecnológica. De acordo com a forma da fronteira, têm-se duas abordagens distintas - a paramétrica e a não-paramétrica. No primeiro caso, postula-se que a fronteira do conjunto produtivo pode ser representada por uma função de produção caracterizada por parâmetros constantes. Este método foi utilizado, pioneiramente, por Aigner e Chu (1968). Com isso, uma forma funcional para a tecnologia é definida a priori e a estimação é feita, normalmente, através de métodos econométricos. A especificação da função de produção é a maior limitação da abordagem paramétrica, uma vez que as medidas de eficiência podem variar consideravelmente de acordo com a função escolhida.

A forma não-paramétrica não se baseia em uma função especificada a priori. A forma da fronteira do conjunto produtivo é determinada considerando que o conjunto de produção deve satisfazer determinadas propriedades. O método DEA está inserido na abordagem não-paramétrica e emprega a programação matemática para estimar modelos de fronteiras de produção e obter os escores de eficiência. Este método é baseado no trabalho de Farrell (1957), posteriormente popularizado por Charnes et al. (1978).

No DEA, as DMUs realizam tarefas similares e se diferenciam pelas quantidades dos insumos que consomem e dos produtos que resultam. Supõe-se que o conjunto de possibilidade de produção deve satisfazer determinadas

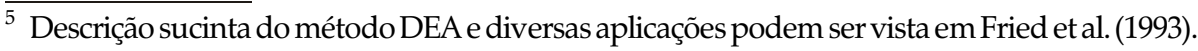


propriedades, mas não há suposições sobre a fronteira propriamente dita. $\mathrm{O}$ modelo proposto por Charnes et al. (1978), com retornos constantes de escala, com $n$ DMUs e utilizando $\boldsymbol{I}$ insumos para produzir $\boldsymbol{P}$ produtos calcula para a i-ésima DMU, uma medida de eficiência. O objetivo é construir uma fronteira não paramétrica que envelope os dados, de forma que todas as unidades se encontrem sobre ou abaixo desta fronteira.

Para cada DMU é maximizada a razão entre a soma ponderada dos produtos e a soma ponderada dos insumos, onde $\boldsymbol{u}$ é um vetor $P \mathbf{x} 1$ dos pesos associados ao produto e $v$ um vetor $I \mathbf{x} \mathbf{1}$ dos pesos associados aos insumos. Os valores de $\boldsymbol{u}$ e $v$ são tratados como incógnitas e calculados de forma a maximizar a eficiência de cada DMU:

$$
\begin{array}{ll}
\operatorname{Max}_{u, v} & \left(u^{t} y_{i} / v^{t} x_{i}\right), \\
\text { Sujeito a } & \left(u^{t} y_{j} / v^{t} x_{j}\right) \leq 1, \quad j=1, \ldots, N, \\
& u \geq 0 \text { e } v \geq 0
\end{array}
$$

O modelo descrito acima apresenta um número infinito de soluções. Pois, se $\left(u^{*}, v^{*}\right)$ é uma solução do problema, então $\left(\alpha u^{*}, \alpha v^{*}\right)$ também é uma solução possível. Esse problema foi resolvido por Charnes et al. (1978) impondo a condição $v^{t} x_{i}=1$, a qual transformou o problema de programação matemática em um problema de programação linear. A nova forma é conhecida como forma multiplicativa e apresenta um grande número de restrições, não sendo adequada para efeitos computacionais. Utilizando a propriedade da dualidade da programação linear, o problema pode ser formulado de uma forma equivalente, porém com menos restrições. O problema de programação linear é resolvido $N$ vezes, uma para cada DMU. O valor de $\theta$ é o escore de eficiência e deve satisfazer a condição $\theta \leq 1$.

$\mathrm{O}$ uso de retornos constantes de escala, quando nem todas as DMUs estão operando na escala ótima, resulta em medidas de eficiência técnica influenciadas pela eficiência de escala. Nestes casos, a abordagem por retornos variáveis de escala permite a medição da eficiência técnica sem essa interferência. A extensão do modelo de retornos constante passa a considerar rendimentos variáveis de escala realizada por Banker et al. (1984), adicionando a restrição de convexidade $\left(z^{t} \lambda=1\right)$.

$$
\begin{array}{ll}
\operatorname{Min}_{\theta, \lambda} & \theta \\
\text { Sujeito a } & Y \lambda-y_{i} \geq 0 \\
& \theta x_{i}-X \lambda \geq 0 \\
& z^{t} \lambda=1 \\
& \lambda \geq 0
\end{array}
$$

Em que $z$ é um vetor unitário $N \times 1$. 
A versão dual do modelo DEA-V, considerando a minimização de insumos é especificada por:

Minimizar $Z_{0}$

$$
\begin{array}{ll}
\text { Sujeito a } & \sum Y_{m j} \lambda_{j} \geq Y_{o} \\
& \sum_{i=1}^{s} X_{i j} \lambda_{j}-X_{o} Z_{o} \leq 0 \\
& \sum \lambda_{i}=1
\end{array}
$$

Para a aplicação em questão, $j=1, \ldots, 348$ é o número de produtores na amostra, $m=1$ representa a produção de cada produtor, $i=1$....,4 é o número de insumos incluídos na análise, $Z_{o}$ é o escore de eficiência relativa do produtor em análise, $\lambda_{j}$ são os pesos que serão obtidos na solução do problemas, e que servirão para compor o(s) produtor (es) de referência para o produtor ineficiente. $X_{i j}$ é o nível do $i$-ésimo insumo sob o j-ésimo produtor, $Y_{m j}$ é o nível do m-ésimo produto sob o j-ésimo produtor, $Y_{o}$ é o nível de produto do produtor ' $o^{\prime}$, e $X_{o}$ é o vetor de insumos usado por este produtor. Os escores de eficiência resultantes variam no intervalo de 0 a 1 com valores mais próximos de 1 indicando melhor eficiência.

\subsection{Abordagem FDH}

Uma característica importante do modelo de fronteira FDH (Free Disposal Hull) é o conceito de dominância (TULKENS, 1993). Um produtor é considerado dominante em relação a outro se obtém uma produção maior com o mesmo nível de insumos, ou com menor quantidade de pelo menos um dos insumos. Os eficientes, mas não dominantes, são chamados "eficientes por default" e são considerados como tais por ausência de produtores na amostra, cujos indicadores sejam semelhantes aos seus.

A estrutura de programação matemática desse modelo é semelhante a do modelo DEA-V, com a introdução de uma restrição, $\lambda_{i} \in\{0,1\}$, que relaxa a suposição de convexidade inerente nos modelos DEA.

Minimizar $\mathrm{Z}_{0}$

$$
\begin{aligned}
\text { Sujeito a } & \sum Y_{m j} \lambda_{j} \geq Y_{o} \\
& \sum_{i=1}^{s} X_{i j} \lambda_{j}-X_{o} Z_{o} \leq 0 \\
& \sum \lambda_{i}=1 \\
& \lambda \in\{0,1\}
\end{aligned}
$$




\subsection{Variáveis e dados utilizados}

A amostra utilizada correspondeu a 348 pequenos e médios produtores de camarão (com áreas inferiores a 50 ha) e foi selecionada a partir do Censo da carcinicultura realizado pela ABCC, em 2004. Foram descartados os produtores que não produziram e os com mais de 50 hectares. A Tabela 1 mostra algumas estatísticas descritivas das variáveis utilizadas nos modelos. Os insumos selecionados foram: área em produção, número total de viveiros, densidade de povoamento e número de empregado. A produção de camarão corresponde ao total obtido durante os ciclos produtivos no ano.

Tabela 1. Estatística descritiva das variáveis utilizadas na estimação das fronteiras de produção, DEA-C, DEA-V e FDH

\begin{tabular}{|c|c|c|c|c|}
\hline Variáveis & Média & $\begin{array}{c}\text { Desv. } \\
\text { Padrão }\end{array}$ & Mínimo & Máximo \\
\hline \multicolumn{5}{|l|}{ Produto } \\
\hline Y - Produção de camarão (toneladas) & 36,7 & 61,4 & 3,0 & 500 \\
\hline \multicolumn{5}{|l|}{ Insumos } \\
\hline$X_{1}$ - Área em produção (hectares) & 7,9 & 9,8 & 0,2 & 50 \\
\hline$X_{2}-$ Número total de viveiros & 3,9 & 4,3 & 1,0 & 40 \\
\hline $\begin{array}{l}X_{3} \text { - Densidade de povoamento } \\
\quad\left(\text { pós larvas por } \mathrm{m}^{2}\right)\end{array}$ & 30,3 & 0,8 & 3,0 & 100 \\
\hline $\mathrm{X}_{4}-$ Número de empregados & 4,9 & 6,3 & 1,0 & 51 \\
\hline Total de Observações - 348 & & & & \\
\hline
\end{tabular}

As variáveis áreas em produção e número total de viveiros representam a disponibilidade de área do produtor e como ele faz a divisão da mesma. A densidade de povoamento mostra como ele aloca as larvas em seu espaço produtivo e o número de empregados indica o uso de mão-de-obra. A eficiência técnica calculada neste trabalho refere-se à melhor utilização destes insumos (listados na Tabela 1) para a obtenção do produto - produção de camarão.

Variáveis que indicam custos poderiam ser incluídas com o intuito de verificar além da eficiência técnica, a eficiência alocativa (que corresponde à utilização de insumos em proporções ótimas, visando a obtenção de custos mínimos), mas não constavam do Censo da $A B C C$ e, portanto, a análise apresentada não considera o fator preços dos insumos, que varia de acordo com a região do estado na decisão de utilização dos mesmos. Contudo, acredita-se que a ineficiência técnica é superior à alocativa na composição da eficiência econômica dos produtores do RN, sobretudo dos pequenos. 
O baixo nível de eficiência pode estar associado a diversos fatores inerentes à atividade da carcinicultura. Uma delas é a gestão da fazenda. Por exemplo, alguns produtores possuem tanques berçários para as pós-larvas que permitem uma maior taxa de sobrevivência dos alevinos, contribuindo, dessa forma, para redução do desperdício de recursos como água, ração, energia e mão-de-obra.

A correção e o tratamento de solos das fazendas são importantes para a criação de camarão, principalmente nas regiões úmidas e esponjosas. Viveiros com solos ácidos sulfatados - $\mathrm{pH}$ abaixo de $0,4-$, além de provocar o aparecimento de algas e bactérias, e conseqüente aparecimento de doenças, pode resultar na morte de animais aquáticos quando ocorre o escoamento da água para os rios e áreas próximas à costa. Espera-se que a prática da correção do solo ajude na redução da ineficiência técnica.

A colocação das rações através do sistema de bandejas reduz o desperdício e ajuda a diminuir a formação de sedimentos no fundo dos viveiros. Elevado nível de resíduos pode provocar a mortalidade de camarões.

Aeradores são aparelhos mecânicos que ajudam a incorporação do oxigênio na água dos viveiros. A utilização desses aparelhos permite a circulação da água, contribuindo, portanto, para o aumento da taxa de sobrevivência.

Produtores que possuem equipamentos de monitoração da qualidade da água podem detectar e corrigir mais rapidamente os problemas decorrentes descritos acima. Esses equipamentos podem indicar os níveis de oxigênio presentes na água, $\mathrm{pH}$, alcalinidade, taxas de amônia, nitrogênio e outros padrões laboratoriais.

A presença de patologias do camarão é um dos principais problemas enfrentados pelos carcinicultores. O surgimento de doenças nessa atividade pode implicar no aumento da taxa de mortalidade, refletindo diretamente na eficiência técnica do produtor.

A ineficiência técnica ainda pode estar associada à localização das fazendas nos diversos estuários existentes na costa litorânea (Figura 1). Alguns estuários, por exemplo, os localizados na região oeste do Rio Grande do Norte, possuem solos com um nível de acidez mais elevado e água mais salobra, o que exige maior nível de correção do solo e controle dos padrões laboratoriais da qualidade da água. Esse é o caso do estuário de Guamaré, localizado próximo à região salineira do estado. Por outro lado, nos estuários de Ceará-Mirim, Guaraíras e Curimataú a qualidade do solo e da água são mais propiciais para a atividade da carcinicultura. 
Figura 1. Mapa mostrando as localizações dos estuários utilizados no estudo, Rio Grande do Norte, Brasil

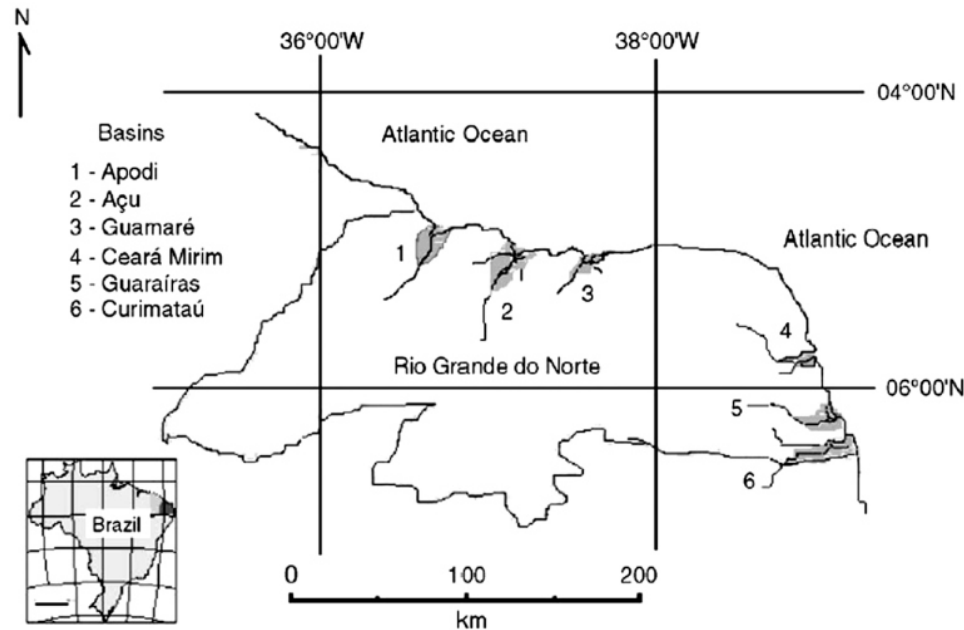

Fonte: Lacerda et al. (2006).

\subsection{Modelo de Regressão Tobit}

Com o objetivo de avaliar os fatores que estariam associados à ineficiência, estimou-se um modelo de regressão Tobit, no qual a variável dependente é o escore de ineficiência dos carcinicultores e as variáveis explicativas são dummies que permitem identificar a presença de tanques berçários, a prática de correção e tratamento dos solos, a utilização de sistema de bandejas para alimentação dos camarões, o uso de aeradores para aumentar a taxa de oxigênio na água, a utilização de equipamentos para o controle da qualidade da água, o surgimento de doenças e a localização das fazendas nos seis estuários.

A variável dependente $Y_{i}^{*}$ é obtida subtraindo da unidade o valor da eficiência técnica dos produtores, isto é, a ineficiência técnica é dada por: $Y_{i}=1-Z_{o}$ resultando em:

$$
\begin{array}{ccc}
Y_{i}^{*}=\gamma+\sum_{i=1}^{n} \beta_{k} W_{k i}+\varepsilon_{i} & \text { se } & \gamma+\sum_{i=1}^{n} \beta_{k} W_{k i}>0 \\
Y_{i}^{*}=0 & \text { se } & \gamma+\sum_{i=1}^{n} \beta_{k} W_{k i} \leq 0
\end{array}
$$

em que, os $W_{k}$, são as variáveis dummies, os coeficientes $\gamma$ e $\beta_{k}{ }^{\prime}$ s são os parâmetros estimados no modelo e os $\varepsilon_{i}$ são os resíduos do modelo, os quais medem variações na ineficiência técnica que não são explicadas pelas variáveis de gestão e localização. 
O modelo de regressão Tobit pertence à classe dos modelos de regressão censoriada, cujos parâmetros são estimados pelo processo de máxima verossimilhança. A sua função de log-verossimilhança é dada por:

$$
\ln L=\sum_{y_{i}>0} 1-\frac{1}{2}\left[\ln \left(2 \pi+\ln \sigma^{2}+\frac{\left(y_{i}-\beta^{\prime} x_{i}\right)}{\sigma^{2}}\right)\right]+\sum_{y_{i}>0} \ln \left[1-\Phi\left(\frac{\left(\beta^{\prime} x_{i}\right)}{\sigma}\right)\right]
$$

Um dos problemas com a estimação desse modelo é a presença de heterocedasticidade. Greene (2000) ressalta que o estimador de máxima verossimilhança é inconsistente diante desse problema, ou seja, se Plim $\hat{\beta}_{k}>\beta_{k}$. Pode-se corrigir a heterocedasticidade fazendo uma suposição sobre a natureza da variância dos erros do modelo. Uma provável especificação, segundo Green (1997) e Maddala (1983) é admitir que $\sigma_{i}^{2}=\exp \left(\alpha^{\prime} z_{i}\right)$.

Prais e Houthakker (1995) consideraram um modelo no qual a variância tem a seguinte especificação: $\sigma_{i}^{2}=\left(\gamma+\alpha z_{i}\right)^{2}$, em que $\gamma$ e $\alpha$ são parâmetros a estimar e $Z_{i}$ é o vetor de variáveis explicativas. O teste para homocedasticidade, baseado na estatística de razão verossimilhança, admite que $\alpha=0$. De acordo com o pressuposto assumido para a variância, o logaritmo da função verossimilhança será dado por:

$$
\begin{aligned}
& \log L(\beta, \gamma, \alpha)=\sum_{y_{i}>0} \log \left[\left(\frac{1}{\sqrt{2 \pi(\gamma+\alpha z)^{2}}}\right) \exp \left\{-\frac{1}{2}\left(\frac{\left(Y_{i}-Z_{i} \beta\right)^{2}}{(\gamma+\alpha z)^{2}}\right)\right]+\right. \\
& +\sum_{y_{i}>0} \log \left[1-\Phi\left(\frac{Z_{i} \beta}{(\gamma+\alpha z)^{2}}\right)\right]
\end{aligned}
$$

Os parâmetros dessa função são estimados pelo método de máxima verossimilhança.

\section{Resultados e discussão}

A Tabela 2 resume a distribuição dos escores de eficiência técnica dos produtores de camarão do RN para os três modelos de fronteiras não paramétricas: análise de envoltória de dados com retornos variáveis de escala, DEA-V, com retornos constantes de escala, DEA-C, e com livre descarte de recursos, FDH.

Os resultados do DEA-V mostraram que 43,7\% dos produtores foram classificados como eficientes. Considerando a suposição de retornos constantes de escala (DEA-C), apenas $2,9 \%$ dos produtores foram eficientes. $\mathrm{O}$ maior percentual de produtores eficientes, $72,1 \%$, foi obtido no FDH, o que era esperado dado que este é menos restritivo do que os modelos DEA. 
Tabela 2. Distribuição dos produtores por classes de eficiência técnica

\begin{tabular}{|c|c|c|c|c|c|c|}
\hline \multirow{2}{*}{$\begin{array}{l}\text { Classe de } \\
\text { Eficiência } \\
\text { Técnica }\end{array}$} & \multicolumn{2}{|c|}{ № de produtores } & \multicolumn{2}{|c|}{ № de produtores } & \multicolumn{2}{|c|}{ № de produtores } \\
\hline & 1 & $0,3 \%$ & 106 & $30,5 \%$ & 0 & $0,0 \%$ \\
\hline $0,2-0,4$ & 40 & $11,5 \%$ & 125 & $35,9 \%$ & 3 & $0,9 \%$ \\
\hline $0,4-0,6$ & 101 & $30,0 \%$ & 74 & $21,3 \%$ & 18 & $5,2 \%$ \\
\hline $0,6-0,8$ & 45 & $12,9 \%$ & 25 & $7,2 \%$ & 45 & $12,9 \%$ \\
\hline $0,8-1$ & 9 & $2,6 \%$ & 8 & $2,3 \%$ & 31 & $8,9 \%$ \\
\hline 1 & 152 & $43,7 \%$ & 10 & $2,9 \%$ & 251 & $72,1 \%$ \\
\hline \multirow[t]{2}{*}{ Total } & 348 & $100,0 \%$ & & $100 \%$ & 348 & $100 \%$ \\
\hline & \multicolumn{2}{|c|}{ DEA - V } & \multicolumn{2}{|c|}{ DEA - C } & \multicolumn{2}{|c|}{ FDH } \\
\hline Mínima & \multicolumn{2}{|c|}{0,19} & \multicolumn{2}{|c|}{0,01} & \multicolumn{2}{|c|}{0,33} \\
\hline Média & \multicolumn{2}{|c|}{0,73} & \multicolumn{2}{|c|}{0,26} & \multicolumn{2}{|c|}{0,91} \\
\hline Máxima & \multicolumn{2}{|c|}{1,00} & \multicolumn{2}{|c|}{1,00} & \multicolumn{2}{|c|}{1,00} \\
\hline
\end{tabular}

Fonte: A partir dos resultados da modelagem.

Dentre os modelos DEA pode-se escolher o mais adequado para a amostra, através de um teste de hipótese de retornos de escala apresentado em Banker (1996), o qual verifica qual a hipótese de retornos de escala - constante ou variável - é mais plausível para o conjunto de dados utilizados. Quando nenhuma suposição sobre a distribuição da ineficiência é considerada nos modelos, Banker sugere a aplicação do teste não-paramétrico de duas amostras de Kolmogorov-Smirnov que é baseado na distância máxima das distribuições acumuladas dos escores de eficiência dos modelos DEA-C e DEA-V. A estatística do teste de Smirnov é representada por:

$$
T_{S M}=\max \left\{F\left(\theta_{D E A C}\right), F\left(\theta_{D E A V}\right)\right\}
$$

em que $F\left(\theta_{D E A C}\right)$ e $F\left(\theta_{D E A V}\right)$ são as distribuições de ineficiência acumuladas dos modelos DEA-C e DEA-V. No procedimento do teste, a estatística $T_{S M}$ é comparada com o valor crítico de $D$ obtido por meio da fórmula:

$$
D=1,36 \sqrt{\frac{n_{1}+n_{2}}{n_{1} n_{2}}}
$$

Os valores encontrados para $T_{S M}=0,546$ e $D=0,103$ permitem rejeitar a hipótese nula $\mathrm{H} 0$ de retornos constantes de escala em relação à hipótese alternativa $H_{A}$ de retornos variáveis de escala. Assim, limita-se a análise comparativa das eficiências dos carcinicultures obtidas no FDH com as do DEA-V. 


\subsection{Eficiência e sistema de produção}

A Tabela 3 mostra o número de produtores por sistemas de produção e a correspondente eficiência técnica média. Esses sistemas são definidos de acordo com a densidade de pós-larva por tanque de criação. O sistema de produção extensivo se caracteriza pela criação de camarão com densidade inferior a 20 camarões $/ \mathrm{m}^{2}$ e nele foram observados 61 produtores, os quais apresentaram eficiência técnica média de 0,74 . Classificaram-se 237 produtores no sistema semi-intensivo - produção entre 20 e 50 camarões $/ \mathrm{m}^{2}$ - os quais apresentaram uma eficiência técnica média de 0,74 . Os 50 carcinicultores do sistema intensivoprodução entre 50 e 100 camarões $/ \mathrm{m}^{2}$ - apresentaram uma eficiência técnica média de 0,72 . Observa-se que não houve diferença significativa de eficiência, com base no DEA-V, entre os carcinicultores por sistemas de produção.

Tabela 3. Distribuição da eficiência técnica dos produtores por sistema de produção, modelo DEA-V

\begin{tabular}{lcccc}
\hline $\begin{array}{l}\text { Sistema de } \\
\text { produção }\end{array}$ & $\begin{array}{c}\text { Pós-larva } \\
\text { (camarão/m² }\end{array}$ & $\begin{array}{c}\text { Número de } \\
\text { produtores }\end{array}$ & $\begin{array}{c}\text { Eficiência } \\
\text { técnica média }\end{array}$ & $\%$ \\
\hline Extensivo & $<20$ & 61 & 0,737 & 73,7 \\
Semi-intensivo & 20 a 50 & 237 & 0,736 & 73,6 \\
Intensivo & 50 a 100 & 50 & 0,720 & 72,0 \\
\hline
\end{tabular}

Fonte: Elaboração dos autores a partir do Censo da carcinicultura, ABCC 2004.

Os resultados do modelo FDH (Tabela 4) revelaram um nível de eficiência média mais alta que o do DEA-V para os sistemas de produção. O sistema extensivo obteve média de 0,95 ; o semi-intensivo, 0,91 ; e o intensivo, 0,88 . Assim, apesar da pequena variação da eficiência média dos sistemas, constatou-se melhor desempenho, em ambos os métodos, para os produtores dos sistemas extensivo e semi-intensivo.

Tabela 4. Distribuição da eficiência técnica dos produtores por sistema de produção, modelo FDH

\begin{tabular}{lcccc}
\hline $\begin{array}{l}\text { Sistema de } \\
\text { produção }\end{array}$ & $\begin{array}{c}\text { Pós-larva } \\
\text { (camarão/m² }\end{array}$ & $\begin{array}{c}\text { Número de } \\
\text { produtores }\end{array}$ & $\begin{array}{c}\text { Eficiência } \\
\text { técnica média }\end{array}$ & $\%$ \\
\hline Extensivo & $<20$ & 61 & 0,958 & $95,8 \%$ \\
Semi-intensivo & 20 a 50 & 237 & 0,910 & $91,0 \%$ \\
Intensivo & 50 a 100 & 50 & 0,881 & $88,1 \%$ \\
\hline
\end{tabular}

Fonte: Elaboração dos autores a partir do Censo da carcinicultura, ABCC 2004. 


\subsection{Eficiência técnica na carcinicultura e meio ambiente}

Tomando como referência a divisão dos estuários de Lacerda et al. (2006), foram analisadas as eficiências dos grupos de municípios classificados de acordo com o estuário ao qual pertencem ${ }^{6}$. Assim, a bacia de Apodi incluiu os municípios litorâneos de Tibau, Grossos, e Areia Branca, além dos interioranos Mossoró e Gov. Dix-Sept Rosado; a bacia do Açu incorporou Porto do Mangue, Macau, Carnaubais, Pendências, Alto do Rodrigues, Açu e Ipanguaçu; a bacia Guamaré, o município de mesmo nome e Galinhos; etc.

A área de viveiros coberta pelo estudo de Lacerda foi de 4814 ha, a qual corresponde a cerca de $92 \%$ da área total em operação das fazendas de camarão no RN. A atividade utiliza grandes quantidades de fertilizante e ração para manter a alta produtividade. De acordo Nunes, apud Lacerda, (2006) as aplicações típicas de fertilizantes atingem 40 e $10 \mathrm{~kg} / \mathrm{ha} /$ ciclo de produção de uréia e superfosfato, respectivamente, assumindo uma taxa de conversão de alimentação de 1,5 a 1,8. Como a atividade tende a ser uniforme em todo o mundo, os autores compararam as taxas calculadas em outros países com as de um monitoramento feito por eles em uma fazenda típica no estado do Ceará. No Ceará, as estimativas médias de emissões de Fósforo (P) e de Nitrogênio (N) foram de 0,05 e de $0,47 \mathrm{~kg} / \mathrm{ha} /$ dia, respectivamente. Na Austrália, as emissões médias de $\mathrm{N}$ e $\mathrm{P}$, em fazendas de camarão, com a mesma tecnologia das utilizadas na área de estudo brasileira, foram de 1,08 e 0,06, respectivamente (BURFORD et al., 2003 apud LACERDA, 2006). No México, as taxas de $\mathrm{N}$ e $\mathrm{P}$ foram de 0,58 e 0,12, respectivamente.

Baseando-se na faixa de emissão dos demais países e do Ceará, eles estimaram as emissões nas bacias do RN. Assim, as emissões de N e P variaram diretamente com a área total de viveiros da bacia. Essas informações são mostradas na Tabela 5, juntamente com a área de viveiros e o número de produtores por estuários, além das eficiências médias calculadas através dos modelos DEA e FDH no presente trabalho. Os carcinicultores do estuário de Apodi apresentaram os menores escores de eficiência média em ambos os modelos. Nesta bacia, também se verificou um elevado índice de emissões de $\mathrm{Ne}$ P. Embora a quantidade de ração não tenha sido utilizada nos modelos de eficiência, o excesso na utilização de outros fatores pode estar correlacionado com o uso de ração. Por exemplo, o excesso na utilização de pós-larva, que caracterizaria baixa eficiência, certamente está associado a uma maior utilização de ração. Considerando que as rações são responsáveis por cerca de $76 \%$ das emissões de nitrogênio (MARTINEZ-CORDERO; LEUNG, 2004), o seu desperdício além da ineficiência técnica pode causar impactos ambientais.

\footnotetext{
${ }^{6}$ A localização dos municípios por estuário foi feita de acordo com o Atlas do Rio Grande do Norte (2005).
} 
Tabela 5. Eficiência média dos carcinicultores e taxas de emissões de nitrogênio (N) e fósforo $(\mathrm{P})$ por estuário

\begin{tabular}{|c|c|c|c|c|c|c|c|c|}
\hline \multirow[b]{2}{*}{ Bacia } & \multirow{2}{*}{$\begin{array}{c}\text { Eficiência } \\
\text { Média } \\
(\text { DEA) }\end{array}$} & \multirow{2}{*}{$\begin{array}{c}\text { Eficiência } \\
\text { Média } \\
\text { (FDH) }^{\mathrm{a}}\end{array}$} & \multirow{2}{*}{$\begin{array}{c}\text { Número } \\
\text { de } \\
\text { produtores }^{\mathrm{b}}\end{array}$} & \multirow{2}{*}{$\begin{array}{c}\begin{array}{c}\text { Área de } \\
\text { viveiros } \\
\text { (ha) }^{b}\end{array} \\
\end{array}$} & \multicolumn{4}{|c|}{ Emissões Poluentes (ton/yr) } \\
\hline & & & & & Nitrogênio $^{c}$ & $\begin{array}{c}\text { Média } \\
\mathbf{N}\end{array}$ & Fósforo ${ }^{c}$ & $\begin{array}{c}\text { Média } \\
\text { P }\end{array}$ \\
\hline Apodi & 0,56 & 0,83 & 22 & 874 & $109-357$ & 233 & $12-28$ & 20 \\
\hline Guamaré & 0,62 & 0,89 & 17 & 414 & $52-169$ & 110,5 & $6-13$ & 9,5 \\
\hline Açu & 0,62 & 0,91 & 19 & 1.679 & $208-686$ & 447 & $22-54$ & 38 \\
\hline Curimataú & 0,62 & 0,88 & 28 & 1.070 & $133-405$ & 269 & $14-35$ & 24,5 \\
\hline Ceará-Mirim & 0,68 & 0,91 & 53 & 30 & $3,7-12,3$ & 8 & $0,4-1,0$ & 0,7 \\
\hline Guaraíras & 0,83 & 0.95 & 187 & 747 & $92-305$ & 198,5 & $10-24$ & 17 \\
\hline
\end{tabular}

Fonte: aResultados dos modelos DEA e FDH deste trabalho; ${ }^{\text {b }}$ dados do Censo da ABCC; cLACERDA et al. (2006).

Como as eficiências médias das bacias são muito próximas, a relação entre eficiência e impacto no meio ambiente deve ser vista com prudência. A bacia de Ceará-Mirim conta com uso bem reduzido de emissões em relação às outras bacias, tanto de $\mathrm{N}$ como de $\mathrm{P}$, contudo, é a de menor área de viveiros (apenas 30 hectares). Sublinha-se, dentre as demais bacias com grandes áreas de viveiros, a de Guaraíras, cujos produtores obtiveram a maior eficiência média $(0,83)$ e cujas estimativas de emissões de $\mathrm{N}$ e $\mathrm{P}$ são as segundas menores, apenas superiores às estimativas de emissões da bacia de Guamaré. Assim, dadas as variáveis utilizadas no cálculo das ineficiências, constatou-se uma relação negativa entre eficiência e emissões poluentes, ou seja, produtores localizados nas bacias com maiores eficiências médias apresentaram menores médias de emissões de poluentes.

\subsection{Fatores explicativos da ineficiência técnica dos carcinicultores: gestão e localização dos estuários}

As estimativas dos parâmetros e função variância da regressão Tobit indicaram a presença de heterocedasticidade nos dados dos dois modelos (explicativos das ineficiências do DEA e do FDH). Em ambas as funções de variância há parâmetros $\alpha$ 's estatisticamente diferentes de zero e, assim, é necessário corrigir o problema da heterocedasticidade. Admitiu-se que a variância segue o comportamento $\sigma_{l}^{2}=\left(\gamma+\alpha z_{i}\right)^{2}$ e em seguida os modelos foram novamente estimados. Os resultados, já incorporando as correções da heterocedasticidade são apresentados na Tabela $6^{7}$.

$\overline{7 \text { A incorporação }}$ da heterocedasticidade no modelo melhorou a significância dos parâmetros das variáveis explicativas. 
Tabela 6. Estimativas dos parâmetros dos modelos Tobit com correção para heterocedasticidade

\begin{tabular}{lrlrl}
\hline Variável dependente: & \multicolumn{2}{c}{ Ineficiência FDH, $\mathbf{y}^{*}$} & \multicolumn{2}{c}{ Ineficiência DEA, $\mathbf{y}^{*}$} \\
\hline Variáveis explicativas & Coeficiente & Prob. & Coeficiente & Prob. \\
\hline Areador & 0.043530 & 0.3962 & -0.092356 & $0.0469^{* *}$ \\
Bandejas & 0.073718 & 0.6903 & 0.385342 & $0.0993^{* * *}$ \\
Equipamento de & 0.164781 & $0.0019^{*}$ & 0.160387 & 0.0008 \\
monitoração da água & 0.088003 & 0.3198 & 0.119686 & $0.0510^{* * *}$ \\
Tanque berçário & -0.214604 & $0.0000^{*}$ & 0.133977 & $0.0712^{* * *}$ \\
Tratamento de solo & 0.069109 & 0.2123 & 0.187826 & $0.0000^{*}$ \\
Doenças & -0.233608 & 0.1138 & -0.134022 & 0.1369 \\
Açu & -0.038877 & 0.7655 & -0.039279 & 0.6928 \\
Apodi & -0.223750 & $0.0066^{*}$ & -0.130767 & $0.0820^{* * *}$ \\
Ceará-Mirim & -0.442168 & $0.0198^{* *}$ & -0.095779 & 0.3119 \\
Curimataú & -0.161853 & 0.2904 & -0.040099 & 0.7810 \\
Guamaré & -0.172580 & $0.0001^{*}$ & -0.308238 & $0.0000^{*}$ \\
Guaraíras & -0.083850 & 0.6558 & -0.290073 & 0.2421 \\
Constante $\gamma$ & & & & \\
Log likelihood & -535.6454 & & -771.9258 & \\
Avg. Log likelihood & -1.539211 & & -2.218177 & \\
Total observações & 348 & & 348 & \\
\hline
\end{tabular}

*significativo a $1 \%,{ }^{* *}$ significativo a $5 \%,{ }^{* * *}$ significativo a $10 \%$.

Fonte: Resultados do modelo Tobit deste trabalho.

A gestão praticada pelos produtores é analisada através da utilização pelos mesmos de equipamentos como aeradores, equipamentos para monitoração da água, tratamento de solo, utilização de tanques berçários etc. A utilização de aeradores nos viveiros contribuiu para redução da ineficiência técnica da carcinicultura, de acordo com o modelo DEA, não apresentando, contudo, significância pelo modelo FDH. O uso adequado dos aeradores nos viveiros eleva o nível de oxigênio na água e ajuda a aumentar a taxa de sobrevivência na criação de camarão. Entretanto, algumas variáveis de gestão mostraram-se não significativas, como por exemplo, a presença de bandejas para ração. Uma possível resposta é a falta de conhecimento do nível adequado do balanceamento da ração que deve ser empregado nas bandejas.

$\mathrm{O}$ uso de equipamentos para monitorar a água se mostrou positivamente associado à ineficiência. Esse é um resultado não esperado, uma vez que os equipamentos permitem detectar os níveis de oxigênio, $\mathrm{pH}$, alcalinidade e nitrogênio, etc., e compará-los com os níveis exigidos em testes laboratoriais. Os produtores podem não estar fazendo o manejo adequado da qualidade da água a partir das respostas do equipamento. 
Um resultado conflitante nos dois modelos foi o sinal do coeficiente da variável representativa da realização de tratamento do solo, o qual foi negativo no modelo FDH, e positivo no DEA, porém significativo apenas a $10 \%$ no último. $\mathrm{O}$ sinal negativo do FDH era esperado, com os produtores que realizam o tratamento do solo sendo os mais eficientes.

Uma outra variável gerencial que não apresentou um sinal esperado na função ineficiência DEA foi aquela que identifica a existência de tanques berçários nas fazendas (também significativa apenas a 10\%).

Com relação à presença de enfermidades nas fazendas, a função ineficiência DEA apresentou uma associação positiva com essa variável. As fazendas que constataram a presença de doenças nos camarões, como o vírus da mancha branca ou de outras doenças, certamente tiveram suas produções prejudicadas e tornaram-se menos eficientes. Entre 2003 e 2004 surgiram doenças como a minecrose infecciosa (IMN) na carcinicultura do estado.

Para ambos os modelos, a ineficiência relacionou-se negativamente com a localização para aqueles produtores dos estuários de Guaraíras e Ceará-Mirim. Este mesmo sinal foi encontrado para o coeficiente da variável dummy do estuário de Curimataú, na função ineficiência FDH, resultado explicado pela qualidade da água e dos solos destas localidades mais propícias para atividade da carcinicultura em comparação com outros estuários localizados próximos às regiões salineiras. Assim, há uma indicação de que a eficiência técnica está relacionada aos estuários menos poluídos.

\section{Conclusões}

Apesar do crescimento da carcinicultura e de sua importância na geração de renda e emprego para o Rio Grande do Norte, alguns fatores como a queda na taxa de câmbio e a redução do preço internacional levaram os produtores a buscarem, no mercado interno, alternativas para a comercialização.

O objetivo desse estudo foi mensurar a eficiência técnica dos produtores e averiguar como os fatores de gestão e a localização das fazendas estão associados aos níveis de ineficiência obtidos.

Produtores dos sistemas extensivo e semi-intensivo apresentaram uma eficiência média mais alta do que aqueles dos sistemas intensivos. Este resultado sugere que os pequenos e médios produtores têm maiores ganhos na produção ao usar uma quantidade de pós-larvas inferior a 50 camarões por $\mathrm{m}^{2}$. $\mathrm{O}$ aumento de pós-larvas nos viveiros amplia os cuidados com a qualidade da água, além de elevar os custos de produção, como energia, mão-de-obra, entre outros. $\mathrm{O}$ sistema intensivo é o mais utilizado nas maiores fazendas, nas quais, além de escala de produção, desenvolvem-se melhores práticas de gestão, como a dosagem certa da alimentação e o controle da qualidade da água. Admite-se, portanto, que, para os pequenos e médios produtores, uma densidade pós-larvas acima desse limite pode implicar em reduções de eficiência. 
Dada a magnitude da atividade no estado do Rio Grande do Norte, a sua importância econômica (na geração de renda e emprego e captação de divisas através das exportações) é, muitas vezes, confrontada com seu impacto ambiental, sobretudo de emissão de poluentes nos estuários e mares onde se localizam as fazendas. Tentou-se relacionar a ineficiência calculada pelos métodos não-paramétricos com estimativas de emissões de poluentes. Como as eficiências médias das bacias são muito próximas, a relação entre eficiência e impacto no meio ambiente deve ser vista com prudência. O destaque foi a bacia de Guaraíras, com grande área de viveiros, cujos produtores obtiveram a maior eficiência média $(0,83)$ e cujas estimativas de emissões de $\mathrm{N}$ e $\mathrm{P}$ são as segundas menores, apenas superiores às estimativas de emissões da bacia de Guamaré. Além disso, a variável dummy para esta bacia, no modelo Tobit, foi significativa e negativa na explicação da ineficiência. Assim, os resultados sugerem uma associação entre eficiência técnica na produção e estuários com menores níveis de emissões de poluentes.

Como possível ação política, sugere-se a realização de cursos de gestão dos recursos e mais especificamente de utilização dos equipamentos (aeradores, tanques berçários, controle da água e do solo), os quais podem resultar em ganhos expressivos de eficiência, o que pode ainda reduzir o impacto ambiental.

\section{Referências Bibliográficas}

ABCC - Associação Brasileira dos Criadores de Camarão. Censo da Carcinicultura Nacional 2004.

Associação Brasileira dos Criadores de Camarão. As Estatísticas da Carcinicultura Brasileira. Disponível em: www.abccam.com.br/Estatisticas.htm. Acesso em: 03 set. 2006.

ATLAS do RIO GRANDE do NORTE, Organização: Diário de Natal, 2ª edição, 2005.

AIGNER, D. J., e CHU, S. F. On Estimating the Industry Production function American Economic Review, 58(4), September, p. 826-839, 1968.

BANKER, R. D.; CHARNES, A.; COOPER, W. W. Some models for estimating technical and scale inefficiencies in data envelopment analysis. Management Science, v. 30, n.9, 1984.

BANKER, R. D. Hypothesis tests using data envelopment analysis. The Journal of Productivity Analysis, 7, p. 139-159, 1996.

BRICKER, S. B.; FERREIRA, J. G.; SIMAS, T. An integrated methodology for assessment of estuarine trophic status. Ecological Modeling, 169, p. 39-60, 2003.

CHARNES, A. W.; COOPER, W. W.; e RHODES, E. “Measurement the Efficiency of Decision Marking Units". European Journal of Operational Research, Amsterdam, v.2, n.6, p. 429-444, November, 1978.

COSTA, E., Y. SAMPAIO. Geração de empregos diretos e indiretos na cadeia produtiva do camarão marinho cultivado. Economia Aplicada, vol.8, no 2, abril-junho 2004. 
FARREL, M. J. The measurement of productive efficiency. Journal of the Royal Statistical Society Series, v. 120, n. 3, p. 253-281, 1957.

FRIED, H. O.; LOVELL, C. A. K. SCHIMIDT, S. S. The measurement of efficiency of production. Oxford: Oxford University Press, 1993.

GUNARATNE, L. H. P. e LEUNG, P. S. Productivity analysis of Asian shrimp industry: the case of Malaysian shrimp culture. World Aquaculture '97, February 19-23, 1977.

GUNARATNE, L. H. P. e LEUNG,P. S. Asian black tiger shrimp industry: a productivity analysis. Paper Presented at the Second Biennial Georgia Productivity Workshop, University of Georgia, Athens, Georgia, November 1- 13, 1996.

GREENE, W. H. Econometric Analysis. 4ª Edição, Prentice-Hall, 2000.

Econometric Analysis. Third Edition, New York University, 1997.

LACERDA, L. D.; VAISMAN, A. G.; MAIA, L. P.; SILVA, C. A. R.; CUNHA, E. M. S. Relative importance of nitrogen and phosphorus emissions from shrimp farming and other anthropogenic sources for six estuaries along the NE Brazilian coast. Aquaculture, 253, 433-446, 2006.

MADDALA, G. Limited Dependent and Qualitative Variables in Econometrics. Cambridge University Press, 1983.

MARTINEZ-CORDERO, F. J. e LEUNG, P. Sustainable aquaculture and producer performance: measurement of environmentally adjusted productivity and efficiency of a sample of shrimp farms in Mexico. Aquaculture, p. 249-268, 2004.

MDIC. Ministério do Desenvolvimento Indústria e Comércio Exterior Aliceweb. http://www.desenvolvimento.gov.br. Acesso: 05/4/2007.

PRAIS, S e HOUTHAKKER, H. The Analysis of Family Budgets. New York, Cambridge University Press, 1995.

ROCHA, I. P.; RODRIGUES, J. A carcinicultura brasileira em 2002. Revista da Associação Brasileira de Criadores de Camarão, Ano 5, n. 1, p. 30-45, 2003.

SOUZA JUNIOR, J. P. Análise de eficiência da produção de camarão marinho em cativeiro no Estado do Ceará. Dissertação de mestrado apresentada ao Departamento de Economia Agrícola/ Mestrado em Economia Rural da Universidade Federal do Ceará, 127 pgs, 2003.

KHAN, A. S.; LIMA, P. V. P. S.; MADRID, R.M.M. Produção de camarão marinho em cativeiro: uma análise de eficiência técnica, alocativa e de custos. Revista de Economia Aplicada, São Paulo - SP, v. 9, n. 2, p. 205-224, 2005.

TAPPIN, A. D. An examination of the fluxes of nitrogen and phosphorus in temperate and tropical estuaries: current estimates and uncertainties. Estuarine, Coastal and Shelf Science, 55, p. 885-901, 2002.

TULKENS, H. On FDH efficiency analysis: some methodological issues and applications to retail banking, courts, in urban transit. The Journal of Productivity Analysis, v. 4, p. 183-219, 1993. 